\title{
Evidence that involucrin, a marker for differentiation, is oxygen regulated in human squamous cell carcinomas
}

\author{
S-C Chou', Y Azuma', MA Varia' and JA Raleigh",I \\ Department of Radiation Oncology, UNC School of Medicine, CB 7512, Chapel Hill, NC 27599, USA
}

\begin{abstract}
The majority of hypoxic cells in squamous cell carcinomas of the head and neck and cervix express involucrin, a molecular marker for differentiation. This raises the question of whether involucrin is an oxygen-regulated protein and, if so, whether it could serve as an endogenous marker for tumour hypoxia. Consistent with oxygen regulation, involucrin protein was found to increase with increasing hypoxia in confluent cultures of moderately differentiated human SCC9 cells. Cells harvested at the point of confluence and exposed to graded concentrations of oxygen revealed a $K_{m}$ of approximately $15 \mathrm{mmHg}$ for involucrin induction. This is similar to $K_{m} \mathrm{~s}$ for $\mathrm{HIF}$ $1 \alpha$, CAIX and VEGF. Involucrin induction showed a steep dependence on $\mathrm{pO}_{2}$ with a transition from minimum to maximum expression occurring over less than an order of magnitude change in $\mathrm{pO}_{2}$. In contrast to SCC9 cells, involucrin was not induced by hypoxia in poorly differentiated SCC4 cells. It is concluded that involucrin is an oxygen-regulated protein, but that differentiation modulates its transcription status with respect to hypoxia induction.

British Journal of Cancer (2004) 90, 728-735. doi: I0.I038/sj.bjc.660I585 www.bjcancer.com

(c) 2004 Cancer Research UK
\end{abstract}

Keywords: hypoxia; differentiation; pimonidazole; involucrin; oxygen regulation

Hypoxia is associated with poor prognosis in squamous cell carcinomas affecting both local control and distant spread (Hockel et al., 1996a,b, 1999; Nordsmark et al, 1996; Fyles et al, 2002; Kaanders et al, 2002). Local control is believed to depend on local radiation response while distant spread is thought to depend, at least in part, on the induction of oxygen-regulated proteins. In order to test this, pimonidazole, an extrinsic marker for tissue hypoxia (Arteel et al, 1995; Kennedy et al, 1997; Varia et al, 1998; Raleigh et al, 1999), with prognostic value (Kaanders et al, 2002) was used to examine whether ORPs such as VEGF (Raleigh et al, 1998a), metallothionein (Raleigh et al, 2000), HIF-1 $\alpha$ (Janssen et al, 2002), Glut-1 (Airley et al, 2003) and CAIX (Olive et al, 2001) were, in fact, associated with cellular hypoxia in human tumours. Unexpectedly, VEGF and metallothionein (MT) were not expressed in the majority of hypoxic cells in squamous cell carcinomas (Raleigh et al, 1998a, 2000) even though these ORPs were induced by hypoxia in experimental systems (Shweiki et al, 1992; Raleigh et al, 1998b; Murphy et al, 1999).

A possible explanation for this apparent anomaly was found in reports that VEGF and MT are expressed in oxygenated basal lamina of normal stratified epithelia and not in more differentiated, suprabasal layers farthest from the blood vessels (Quaife et al, 1994; Sundelin et al, 1997; Viac et al, 1997). This led to the conclusion that VEGF and MT are downregulated by differentiation in stratified epithelia (Quaife et al, 1994; Viac et al, 1997). In analogy with their untransformed counterpart, squamous cell carcinomas often express markers for terminal differentiation in the centre of tumour nests farthest from blood vessels (Roland

*Correspondence: Dr JA Raleigh; E-mail: James_Raleigh@med.unc.edu Received 12 June 2003; revised II November 2003; accepted 19 November 2003 et al, 1996). Pimonidazole binding was known to occur in these regions (Kennedy et al, 1997), and subsequent studies demonstrated that the majority of the hypoxic cells express involucrin, a molecular marker for epithelial cell differentiation (Raleigh et al, 2000). It was concluded, therefore, that the lack of VEGF and MT expression in hypoxic cells was due to downregulation by differentiation. At the same time, it appeared that involucrin might be an oxygen-regulated protein.

Involucrin is a $96 \mathrm{kDa}$ cell envelope protein that appears in free form in the early stages of keratinocyte terminal differentiation. During the late stages of differentiation, involucrin is crosslinked with proteins and lipids to form cornified cell envelopes in the uppermost cells of stratified epithelia (Eckert and Welter, 1996). Five AP-1 consensus sites exist in the promoter region of the involucrin gene with two sites accounting for $80 \%$ of promoter activity (Crish et al, 2002). One site is proximal while the other is distal to the transcription start site. The proximal site is regulated via a mitogen-activated protein kinase pathway that includes $\mathrm{PKC}$, Ras, MEKK1, MEK3 and p38/RK (Efimova et al, 1998). Gel supershift analyses show that junB, junD and Fra-1 are the major AP-1 transcription factors regulating involucrin expression (Eckert and Welter, 1996). However, cotransfection of involucrin promoter constructs with c-jun and c-fos can increase involucrin promoter activity, indicating that c-Jun also stimulates involucrin transcription (Takahashi and Iizuka, 1993; Efimova et al, 1998). Although involucrin had not been identified previously as an ORP, c-Jun/ AP-1 is known to be responsive to hypoxia in squamous cell carcinoma cells (Bandyopadhyay et al, 1995; Laderoute et al, 2002) and it was conceivable that involucrin expression was oxygen regulated.

The present investigation examines whether involucrin is oxygen regulated in an in vitro model comprising moderately 
differentiated SCC9 and poorly differentiated SCC4 squamous cell carcinoma cells (Rheinwald and Beckett, 1980, 1981). The model was of interest because Rice et al (1988) had shown that involucrin increases spontaneously in postconfluent cultures of SCC9 cells. Hypoxia is generated in unstirred, high-density cell cultures (Boag, 1969; Whillans and Rauth, 1980; Jones, 1985; Kaluz et al, 2002) and, although other explanations are possible, it seemed that involucrin might be induced by hypoxia in the SCC9 cultures.

Investigations of potentially useful endogenous markers of hypoxia such as CAIX and Glut-1 have shown that immunostaining for these proteins extends beyond the edges of pimonidazole binding (Olive et al, 2001; Kaanders et al, 2002; Airley et al, 2003). Many oxygen-regulated processes are half maximally induced at oxygen partial pressures $\left(K_{\mathrm{m}}=6-20 \mathrm{mmHg}\right)$ (Leith and Michelson, 1995; Jiang et al, 1996; Chiarotto and Hill, 1999; Wykoff et al, 2000) that would strongly inhibit the binding of nitroimidazole hypoxia markers such as pimonidazole, EF5 and misonidazole $\left(K_{\mathrm{m}}=0.8-2.0 \mathrm{mmHg}\right.$ ) (Franko et al, 1987; Arteel et al, 1995; Gross et al, 1995; Koch et al, 1995). This could account for the immunostaining patterns for Glut-1 and CAIX. If involucrin were also induced in the range of $6-20 \mathrm{mmHg}$, it might be expressed in tumour microregions that did not bind detectable levels of pimonidazole. In order to explore this possibility, the $K_{\mathrm{m}}$ for involucrin expression has been measured in suspension cultures of SCC9 cells.

In poorly differentiated squamous cell carcinomas, involucrin immunostaining is generally weak even in tumour regions that avidly bind pimonidazole (Azuma et al, 2003). This would appear to be inconsistent with oxygen regulation. However, the transcription status of oxygen-regulated genes can be coregulated by differentiation (Webster et al, 1990; Claffey et al, 1992; Quaife et al, 1994; Levy and Kelly, 1997; Viac et al, 1997) and the effect of differentiation on involucrin expression was therefore examined by comparing its expression in moderately differentiated SCC 9 and poorly differentiated SCC4 cells exposed to acute and chronic hypoxia.

\section{MATERIALS AND METHODS}

\section{Chemicals}

The hypoxia marker, pimonidazole hydrochloride (Hypoxyprobe $^{\mathrm{TM}}-1$; Chemicon International Inc., Temecula, CA, USA), was used as previously described (Arteel et al, 1995; Kennedy et al, 1997; Varia et al, 1998; Raleigh et al, 1999, 2000). 4-Nitrophenyl phosphate (alkaline phosphatase substrate), phosphate-buffered saline (PBS) pellets, foetal bovine serum and hydrocortisone (cat \# H-0396) were obtained from Sigma (St Louis, MO, USA). Liquid $3,3^{\prime}$-diaminobenzidine (DAB) peroxidase substrate was obtained from DAKO Corp (Carpinteria, CA, USA). Aqueous 2\% formalin was obtained from Polysciences, Inc. (Warrington, PA, USA). Enzyme-grade polyoxyethylene ether (Brij 35), polyoxyethylenesorbitan monolaurate (Tween 20), tris(hydroxymethyl)aminomethane (Tris), Biomeda Crystal/Mount, ProbeOn Plus glass slides and miscellaneous reagent-grade chemicals were obtained from Fisher Scientific Company (Norcross, GA, USA). Aqua Haematoxylin was obtained from Innovex Biosciences (Richmond, CA, USA). Gas tanks containing certified quantities of oxygen and $5 \% \mathrm{CO}_{2}$ balanced with nitrogen were purchased from National Welders Supply Company, Inc. (Raleigh, NC, USA).

\section{Immunological reagents}

Supernatant from hybridoma clone 4.3.11.3 containing antipimonidazole $\mathrm{IgG}_{1}$ monoclonal antibody at a concentration of $70 \mu \mathrm{g} \mathrm{ml}^{-1}$ (Chemicon International Inc., Temecula, CA, USA) was used for the immunohistochemical detection of protein adducts of reductively activated pimonidazole as described previously (Arteel et al, 1995; Kennedy et al, 1997; Varia et al, 1998). Diluted aliquots of rabbit polyclonal antipimonidazole antisera were used for the enzyme-linked immunosorbent assay (ELISA) of pimonidazole binding to cell lysates (Arteel et al, 1995). A biotin-conjugated $\mathrm{F}\left(\mathrm{ab}^{\prime}\right)_{2}$ fragment of a rabbit anti-mouse IgG was obtained from Accurate Chemical Scientific Corp. (Westbury, NY, USA) and used as the secondary reagent for the immunohistochemical detection of pimonidazole binding. Protein blocker and peroxidase-conjugated streptavidin were obtained from DAKO Corp. An $\mathrm{IgG}_{1}$ mouse anti-human involucrin antibody clone SY5 used for the immunohistochemical detection of involucrin was obtained from Sigma. An ELISA kit containing rabbit anti-human involucrin antisera and affinity-purified goat anti-rabbit IgG conjugated to alkaline phosphatase used to detect involucrin in cell lysates were obtained from Biomedical Technologies Inc. (Stoughton, MA, USA).

\section{Confluent cell culture}

SCC9 and SCC4 cell lines derived from a squamous cell carcinoma of the human tongue (American Type Culture Collection, Rockville, MD, USA) were grown in Dulbecco's modified eagle medium/ F12 containing $1.0 \mathrm{~mm}$. calcium ion concentration and supplemented with $10 \%$ foetal bovine serum, $0.4 \mu \mathrm{g} \mathrm{ml}^{-1}$ of hydrocortisone and $14 \mathrm{~mm}$ of sodium bicarbonate. Cells were seeded at a density of $3 \times 10^{5}$ cells in 100 -mm diameter culture dishes. Every 3 days, the culture medium was exchanged with fresh medium containing $100 \mu \mathrm{M}$ pimonidazole hydrochloride as hypoxia marker. Cell samples were harvested at 1, 4, 6, 9 and 12 days after confluence. Harvested cells were washed three times with cold PBS and cell densities were measured by cytometry. Cells were lysed in cold buffer containing $0.2 \mathrm{~mm}$ EDTA, $10 \mathrm{~mm}$ Tris, $0.5 \%$ Triton X-100 and $200 \mu \mathrm{l} / 10^{6}$ cells of proteinase inhibitors $\left(1.0 \mu \mathrm{g} \mathrm{ml}^{-1}\right.$ of Leupeptin, $1.0 \mu \mathrm{g} \mathrm{ml}^{-1}$ of pepstatin and $1 \mathrm{~mm}$ phenylmethylsulphonyl fluoride) (Gaido and Maness, 1994). Cell lysates were stored at $-80^{\circ} \mathrm{C}$ until they were analysed by ELISA for pimonidazole adducts and involucrin.

\section{Immunostaining confluent cultures for involucrin and pimonidazole adducts}

SCC9 cells were added to a six-well tissue culture plate at a density of $10^{5}$ cells per well. Each well contained four $22 \mathrm{~mm}$ square cover glass slides to which the cells attached. At 2 days prior to confluence, at confluence and 5 days after confluence, cells on the glass slides were fixed with $2 \%$ of formaldehyde in PBS for $20 \mathrm{~min}$. The slides were washed and permeabilised with $0.02 \%$ of saponin in PBS containing $5 \%$ of serum-free protein block for $30 \mathrm{~min}$. Fixed cells were incubated with antipimonidazole $\operatorname{IgG}_{1}$ monoclonal antibody 4.3.11.3 (1:50) and anti-human involucrin monoclonal antibody $(1: 100)$ for $1 \mathrm{~h}$. The cells were then incubated with biotin-conjugated rabbit anti-mouse $\mathrm{F}\left(\mathrm{ab}^{\prime}\right) 2$ IgG antibody $(1: 500)$ for $30 \mathrm{~min}$. The cells were incubated with streptavidin-conjugated peroxidase for $20 \mathrm{~min}$ and colour developed by incubation with $\mathrm{DAB}$ for $10 \mathrm{~min}$. The cells were counterstained with haematoxylin at room temperature for $25 \mathrm{~s}$ and washed. The cover slides were placed on a microscope slide, with the cells facing the surface of the microscope slide and mounted with CrystalMount.

\section{Exposure of cells to hypoxia in suspension culture}

When SCC9 and SCC4 cells reached confluence they were trypsinised and collected. Aliquots of $5 \times 10^{6}$ cells in $25 \mathrm{ml}$ of culture medium containing $100 \mu \mathrm{m}$ pimonidazole hydrochloride and $1.0 \mathrm{~mm}$ calcium ion were added to $250 \mathrm{ml}$ glass vessels fitted with PTFE inlet and outlet stopcocks and a small diameter injection port (cat.\# 7401-50; Ace Glass, Inc., Vineland, NJ, USA). 
In order to minimise cell adhesion, the vessels were silanised by treatment with Sigmacote (Sigma, St Louis, MO, USA) followed by extensive washing with distilled water. Cells were kept in suspension by attaching the gassing vessel to the deck of an orbital shaker (Model SS110504; Integrated Separation Systems, Natick, MA, USA) in a warm room maintained at $37^{\circ} \mathrm{C}$. The system was flushed for $20 \mathrm{~min}$ in order to remove oxygen dissolved in nonglass components of the system. These included two PTFE stopcocks, a small red rubber septum port, PTFE unions connecting gas wash bottles to nylon transmission tubing (12723 Universal Connector; Ace Glass, Inc.), short lengths of flexible tygon tubing that connected reciprocating glass tubes to stiff, lowpermeability $3 / 16$ inch internal diameter nylon transmission tubing (A-06489-06; Cole-Palmer Instrument Co., Vernon Hills, IL, USA) and $150 \mathrm{ml}$ of distilled water in a gas wash bottle used to humidify the gas stream. Following flushing, the system was subjected to 12 rounds of partial vacuum followed by pressurisation with gas phases containing 10,100,500,5000, 10000,20000 or $25000 \mathrm{ppm}$ oxygen and $5 \% \mathrm{CO}_{2}$ balanced with nitrogen. The gas exchanges - which were carried out over a period of $5 \mathrm{~min}-$ facilitated the rapid equilibration of molecular oxygen in gas and aqueous phases. Once equilibrated, cells were incubated with shaking under a continuous flow of gas. Previous studies showed that cell viability is not affected by this procedure (Arteel et al, 1995). Teflon and nylon have low oxygen permeability (see ColePalmer Instrument Company 2003/04 catalogue, p.1910) and once flushed were not expected to be a source of oxygen contamination. Rubber and tygon are more permeable, but oxygen contamination from rubber septa and short lengths of tygon tubing was also considered to be insignificant in a system equilibrated and then continuously flushed with a flow of gas. Whillans and Rauth (1980) have shown that continuous flushing following equilibration is adequate to control $\mathrm{pO}_{2}$ down to at least $0.01 \%$ even when relatively long sections of tygon tubing are used.

The $K_{\mathrm{m}}$ experiment was repeated twice and the data points averaged for both pimonidazole binding and involucrin expression. Control experiments showed that the presence of pimonidazole did not affect involucrin expression. Cells were collected, washed three times with cold PBS and cell densities were measured by cytometry. Cells were lysed and stored at $-80^{\circ} \mathrm{C}$ for subsequent ELISA analysis for involucrin and pimonidazole adducts.

\section{ELISA}

The ELISA for pimonidazole adducts followed a previously published method for 2-nitroimidazole hypoxia markers (Raleigh et al, 1994; Thrall et al, 1994; Arteel et al, 1995), except that cell lysates were prepared by homogenisation without pronase $\mathrm{K}$ digestion. Briefly, $100 \mu \mathrm{l}_{\text {well }}{ }^{-1}$ of serial dilutions of cell lysates and serial dilutions of pimonidazole hydrochloride standards were incubated for $1 \mathrm{~h}$ at $37^{\circ} \mathrm{C}$ in 96 -well microtitre plates containing $100 \mu \mathrm{lwell}^{-1}$ of rabbit polyclonal antipimonidazole antisera diluted 6:10000 in PBS-Tween (0.05\% Tween 20 in PBS). The mixtures were transferred to ELISA plates coated with a Ficoll-pimonidazole conjugate as solid-phase antigen and the plates incubated for $1 \mathrm{~h}$ at $37^{\circ} \mathrm{C}$. The plates were washed with PBS-Tween by means of an Ultrawash plate washer (Dynex Technologies Inc., Chantilly, VA, USA); $100 \mu \mathrm{lwell}^{-1}$ of a 1:2000 goat anti-rabbit antibody conjugated with alkaline phosphatase was added, and the plates were incubated for $1 \mathrm{~h}$ at $37^{\circ} \mathrm{C}$. The plates were washed and $100 \mu \mathrm{lwell}^{-1}$ of a $1 \mathrm{mg} \mathrm{ml}^{-1}$ solution of alkaline phosphatase substrate dissolved in $10 \%$ diethanolamine $\mathrm{pH} 9.8$ buffer was added. Colour development at $405 \mathrm{~nm}$ was followed for $5 \mathrm{~min}$ by means of a Molecular Devices plate reader. Kinetic data were analysed by means of Vmax DeltaSoft 3 software (Biometallics, Inc., Princeton, NJ, USA). ELISA data were corrected for the fact that pimonidazole hydrochloride, although a convenient standard, is 25 less effective as a competitive inhibitor than protein adducts of pimonidazole (Arteel et al, 1995). The data were normalised to cell lysate protein content as measured by the Bio-Rad Dc protein assay (Bio-Rad, Hercules, CA, USA) using bovine serum albumin as a standard.

The involucrin ELISA kit was used according to the directions provided by Biomedical Technologies Inc. In the final step, a secondary goat anti-rabbit IgG-conjugated alkaline phosphatase was used to detect the binding of the antiinvolucrin rabbit antisera to involucrin solid phase antigen. End point colour development at $405 \mathrm{~nm}$ associated with the hydrolysis of 4-nitrophenyl phosphate was recorded after $30 \mathrm{~min}$. ELISA data for involucrin were normalised for protein content in the cell lysates using bovine serum albumin as a standard.

\section{Clinical samples}

Contiguous tumour sections immunostained for involucrin and pimonidazole binding were available from head and neck squamous cell carcinomas from an earlier study (Raleigh et al, 2000). The study had received local Institutional Review Board approval for the type of experiment described here. Patients enrolled in the study had signed informed consent forms prior to their participation in the study (Raleigh et al, 2000). The Hypoxyprobe-1 used for the clinical studies was obtained from NPI, Incorporated (Belmont, MA, USA).

\section{RESULTS}

\section{Involucrin and hypoxia in confluent cultures of SCC9 and SCC4 cells}

ELISA measurements revealed a steady increase in involucrin expression in SCC9 cells beginning ca 4 days postconfluence. The increase in involucrin expression was associated with an increase in pimonidazole binding in the cultures. The maximum involucrin protein expression occurred ca 9 days postconfluence (Figure 1). Pimonidazole binding increased in confluent cultures of SCC4 cells but, unlike SCC9 cells, a corresponding increase in involucrin did not occur (Figure 2).

Immunostaining of postconfluent SCC9 cell cultures showed punctate patterns for both involucrin expression and pimonidazole binding. That is, the whole culture was not hypoxic but rather subsets of cells within the cultures formed pimonidazole adducts (data not shown). Owing to piling up in the cultures, it has not been possible to determine whether pimonidazole-positive cells are also involucrin positive by microscopic examination of dual stained slides (data not shown).

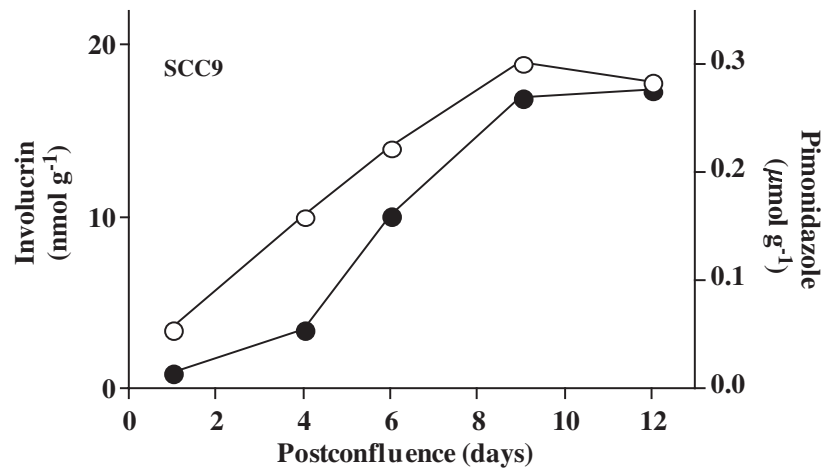

Figure I Involucrin expression (solid circles) and pimonidazole binding (open circles) in moderately differentiated SCC9 cells growing in confluent culture in the presence of $1.0 \mathrm{~mm}$ calcium ion. The increase in involucrin expression more or less parallels that for pimonidazole binding. The involucrin data are similar to those reported by others (Rice et al, 1988). 


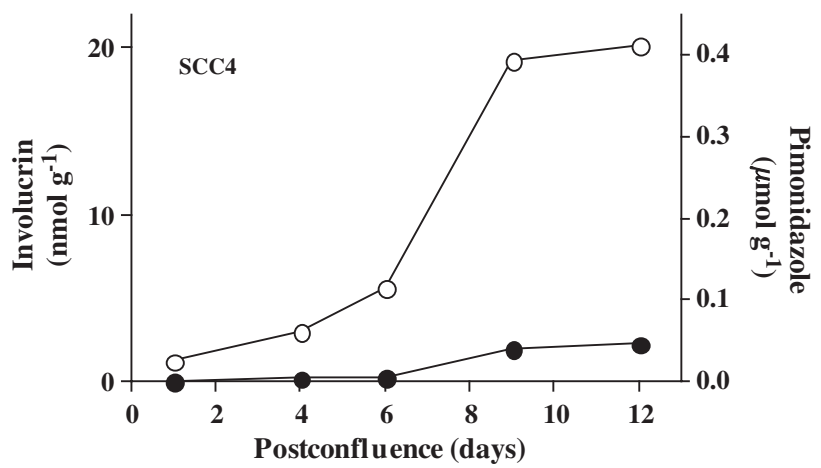

Figure 2 Involucrin expression (solid circles) and pimonidazole binding (open circles) in poorly differentiated SCC4 cells growing in confluent culture in the presence of $1.0 \mathrm{~mm}$ calcium ion concentration. Little or no involucrin is induced in the cultures, even though pimonidazole binding indicates the presence of hypoxia in the cultures.

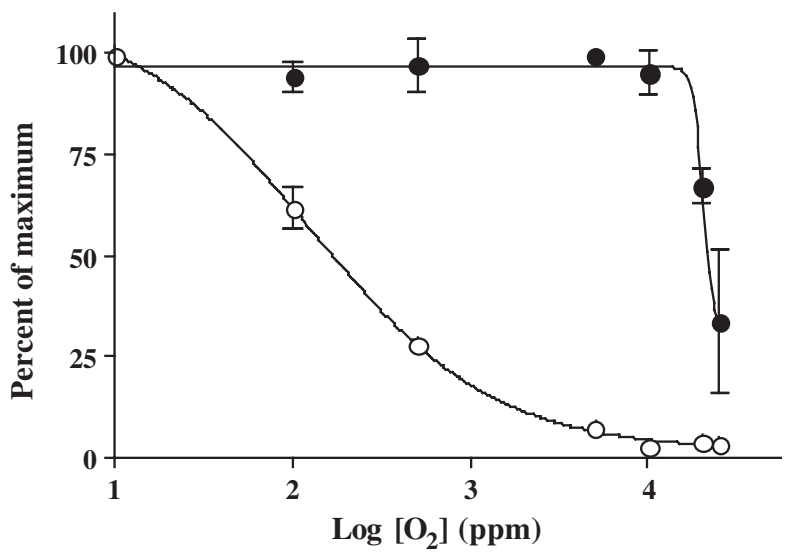

Figure $3 \quad K_{m}$ curves for involucrin (solid circles) and pimonidazole binding (open circles) in SCC9 cells exposed for $2 \mathrm{~h}$ to different $\mathrm{pO}_{2}$ in the presence of $1.0 \mathrm{mM}$ calcium ion concentration. The data represent averages of two independent experiments. Range of data for the two experiments is shown where it exceeded the dimension of the data symbol. Note the 40fold difference in $K_{m}$ between involucrin induction and pimonidazole binding and the steep $\mathrm{pO}_{2}$ dependence for involucrin induction.

\section{$K_{\mathrm{m}}$ for involucrin expression in suspension cultures of SCC9 cells}

Involucrin induction was half maximal at a gas phase oxygen concentration of approximately $20000 \mathrm{ppm}$ for SCC9 cells harvested at the point of confluence and exposed to graded concentrations of oxygen for $2 \mathrm{~h}$ (Figure 3 ). A gas phase concentration of $20000 \mathrm{ppm}$ is equivalent to a partial pressure of $15 \mathrm{mmHg}$, a gas phase concentration of $2 \%$ or a dissolved oxygen concentration of $21 \mu \mathrm{m}$ at $37^{\circ} \mathrm{C}$. Cells harvested 9 days postconfluence, when involucrin expression was at a maximum, showed no additional induction of involucrin during acute exposure to hypoxia in suspension culture. As was the case in confluent cultures, involucrin was not induced in SCC4 cells during hypoxic exposure in suspension culture.

The $K_{\mathrm{m}}$ for involucrin induction was ca 40 times higher than that for pimonidazole binding in SCC9 cells (Figure 3). Furthermore, the oxygen dependence for involucrin expression in SCC9 cells was much steeper than that for pimonidazole binding, increasing from minimum to maximum over less than one order of magnitude change in $p \mathrm{O}_{2}$ compared to pimonidazole binding that rose from minimum to maximum over two orders of magnitude as expected for a competition between pimonidazole and oxygen for reducing equivalents (Arteel et al, 1998).

\section{Immunostaining patterns for involucrin and hypoxia in head and neck squamous cell carcinomas}

Figure 4 shows representative examples of immunostaining for involucrin expression and pimonidazole binding in contiguous sections taken from squamous cell carcinomas of the head neck. Figure $4 \mathrm{~A}$ and $\mathrm{B}$ are derived from a well-differentiated (Grade 1) squamous cell carcinoma of the floor of the mouth. In this case, immunostaining for involucrin extends well beyond the edges of immunostaining for pimonidazole adducts and, in some regions, involucrin is expressed in the absence of pimonidazole binding. Figure $4 \mathrm{C}$ and $\mathrm{D}$ are derived from a moderately differentiated (Grade 2) tumour of the larynx. In this case, the extent of immunostaining for involucrin conforms more closely to that for pimonidazole adducts, with the extent of immunostaining differing by a factor of only ca 1.5. Figure $4 \mathrm{E}$ and $\mathrm{F}$ are derived from a poorly differentiated (Grade 3) squamous cell carcinoma of the larynx. In this case, little or no involucrin is expressed even in the presence of substantial amounts of pimonidazole binding.

\section{DISCUSSION}

Involucrin expression increases with increasing hypoxia in confluent cultures of SCC9 cells consistent with the idea that involucrin is an oxygen-regulated protein. The induction of involucrin during hypoxic exposure of SCC9 cells in suspension culture confirms that involucrin can be induced by hypoxia in moderately differentiated squamous cell carcinoma cells. Induction occurs over a period of $2 \mathrm{~h}$ and is, therefore, relatively rapid. In contrast to SCC9 cells, hypoxia induces little or no involucrin in poorly differentiated SCC4 cells in spite of the fact that the involucrin gene is reported to be functional with ample quantities of involucrin mRNA present in these cells (Gibson et al, 1996). Interestingly, Gibson et al observed a distinction between welldifferentiated keratinocytes and poorly differentiated SCC4 cells with respect to calcium ion-induced involucrin expression. In particular, high calcium concentration induced involucrin mRNA and protein in keratinocytes but not in poorly differentiated SCC4 cells (Gibson et al, 1996). This similarity between calcium and hypoxia regulation might be important for understanding how hypoxia induces involucrin. For example, Salnikow et al (2002) have described an HIF- $1 \alpha$ independent pathway for the hypoxia induction of AP-1 regulated genes in which hypoxia-induced intracellular calcium release and subsequent interaction at AP-1 promoter sites are key events. Calcium ion concentration is known to increase in the outer layers of stratified epithelia (Denda et al, 2000) and it is conceivable that hypoxia interacts with calcium ions to stimulate the production of involucrin and other AP-1dependent proteins. Experiments are underway to test whether the effect hypoxia on involucrin induction is direct or one mediated by intracellular calcium ions. It should be noted that the process of differentiation itself is initiated in the well-oxygenated basal cells of stratified epithelia (Watt, 1983) and is unlikely, therefore, to be initiated by hypoxia.

Involucrin induction has a time course similar to that for pimonidazole binding but is distinguished by a very steep dependence on $\mathrm{pO}_{2}$. A similarly steep dependence has been reported for VEGF mRNA induction in a number of cell lines (Chiarotto and Hill, 1999). This steepness of response is reminiscent of synergistic interactions and it is tempting to speculate that these might involve interactions between hypoxia and calcium ions reported for the case of VEGF (Salnikow et al, 2002). Involucrin induction is further distinguished from pimonidazole binding in that the $K_{\mathrm{m}}(15 \mathrm{mmHg})$ is similar to that for 


\section{Involucrin}
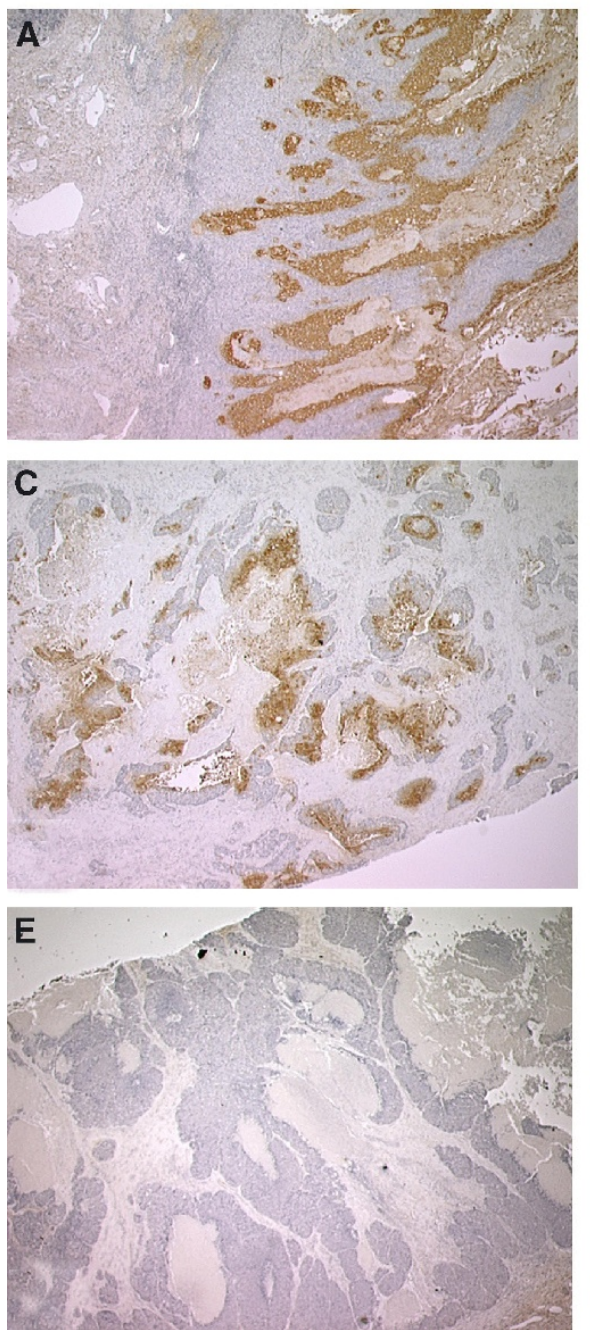

\section{Pimonidazole}
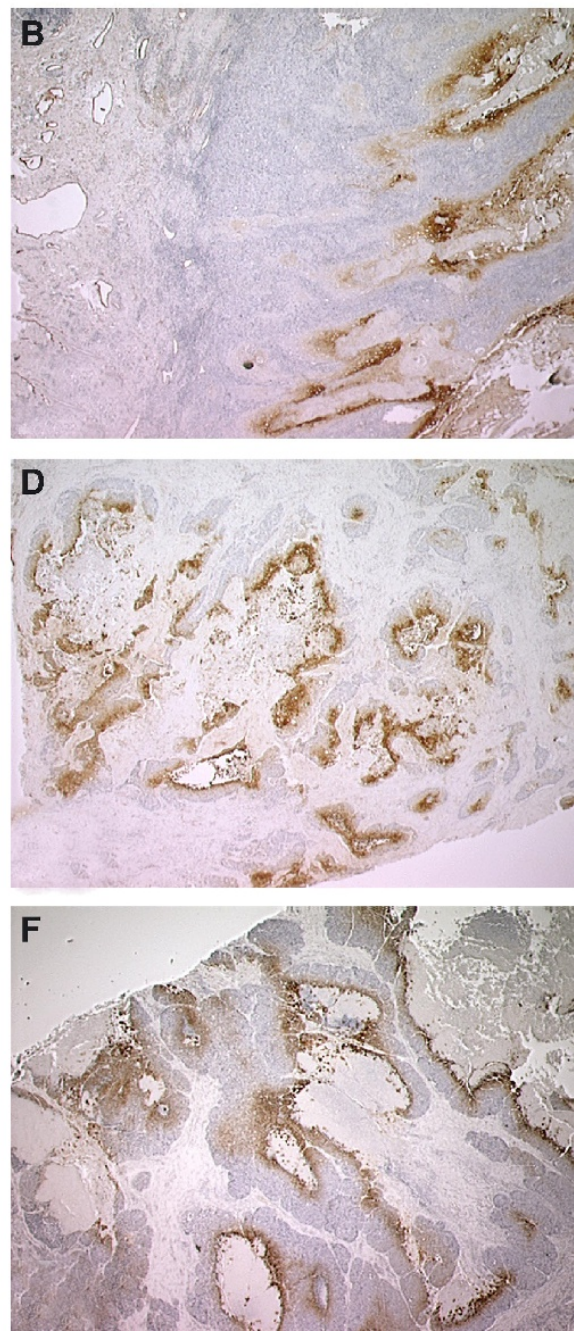

Figure 4 Immunostaining patterns for involucrin expression (left panels) and pimonidazole binding (right panels) in contiguous sections from squamous cell carcinomas (SCC) of the head and neck. (A and B) Immunostaining for involucrin and pimonidazole adducts, respectively, in sections from a Grade I floor of the mouth SCC. (C and D) Immunostaining for involucrin and pimonidazole adducts in sections from a Grade 2 larynx SCC. Immunostaining for involucrin (A) extends well beyond that for pimonidazole binding (B) and is expressed in the absence of pimonidazole binding in some microregions. (C and D) Immunostaining for involucrin and pimonidazole adducts is closely matched with the extent of involucrin immunostaining covering an area ca 1.5 that for pimonidazole. (E and $\mathbf{F}$ ) Immunostaining for involucrin and pimonidazole adducts in sections from a Grade 3 larynx SCC. Little or no involucrin expression is observed in the presence of extensive pimonidazole binding. Original magnification: $\times 12.5$.

VEGF (Leith and Michelson, 1995; Chiarotto and Hill, 1999) and, therefore, ca 40 times higher than that for pimonidazole binding $(0.4 \mathrm{mmHg})$. The rapid rate of induction, steep $\mathrm{pO}_{2}$ dependence and high $K_{\mathrm{m}}$ could be important in understanding immunostaining patterns for involucrin in squamous cell carcinomas.

In well-differentiated tumours, immunostaining for involucrin is more extensive than that for pimonidazole binding and in some areas, involucrin is expressed in the absence of pimonidazole binding (Figure 4A and B; Azuma et al, 2003). Superficially, a 40fold difference in $K_{\mathrm{m}}$ for involucrin induction and pimonidazole binding might account for this. However, it does not explain why immunostaining for involucrin more closely matches pimonidazole binding in moderately differentiated tumours (Figure $4 \mathrm{C}$ and D) where the extent of immunostaining differs by a factor of only ca 1.5. A similar small factor of ca 2 has been reported for the difference between the extent of CAIX expression and pimonidazole binding in squamous cell carcinomas (Olive et al, 2001). One explanation is that different levels of acute hypoxia exist in the two tumours (Pigott et al, 1996). That is, the more extensive immunostaining for involucrin is due to rapid induction during acute changes in hypoxia that pimonidazole binding cannot match. However, both pimonidazole binding and involucrin are easily detected within $2 \mathrm{~h}$ of hypoxic exposure in vitro making this explanation less likely. A second possibility is that hypoxia developed during the time between pimonidazole washout (plasma $t_{1 / 2}=\mathrm{ca} 5 \mathrm{~h}$ ) and tumour biopsy, but this would require a major change in oxygen distribution in the tumour depicted in Figure $4 \mathrm{~A}$ and $B$, which seems unlikely.

A third possible explanation for immunostaining patterns in Figure 4 is that oxygen gradients are steeper in moderately differentiated tumours than in well-differentiated tumours. Steep oxygen gradients would foreshorten the distance over which divergent $K_{\mathrm{m}} \mathrm{s}$ are traversed, possibly reducing the distance to the two or three cell diameters observed in moderately differentiated tumours (Figure 4C and D) and in normal tissues such as the liver and kidney (Arteel et al, 1995; Zhong et al, 1998). Conversely, 
shallow gradients would increase the distance over which divergent $K_{\mathrm{m}} \mathrm{s}$ are traversed allowing for involucrin induction in advance of pimonidazole binding as appears to be the case in Figure 4A and B. Variations in the slope of oxygen gradients have been proposed to account for the lack of nitroimidazole binding around areas of necrosis in a subset of glioma xenografts (Parliament et al, 1997; Franko et al, 1998; Turcotte et al, 2002), but it remains to be seen whether this occurs among subsets of squamous cell carcinomas.

Poorly differentiated tumours express very little involucrin even in the areas of extensive pimonidazole binding. This is observed for squamous cell carcinomas of the head and neck (Figure $4 \mathrm{E}$ and F) and uterine cervix (Azuma et al, 2003). While this does not appear to be consistent with oxygen regulation, it matches in vitro data where involucrin is induced by hypoxia in moderately differentiated SCC9 cells but not in poorly differentiated SCC4 cells. While there is no basis for believing that the mechanism that prevents involucrin induction in SCC4 cells is exactly the same as that which prevents involucrin expression in the hypoxic regions of poorly differentiated squamous cell carcinomas, the model system does show that dedifferentiation can suppress involucrin induction by hypoxia.

Hypoxia inhibits differentiation in some cell lines (Sahai et al, 1997) and possibly in breast carcinomas (Helczynska et al, 2003), but the association between hypoxia and involucrin expression (Figures 1, 3 and 4) indicates that this might not be true for squamous cell carcinomas. It is important to emphasise, however, that involucrin is an early marker for terminal differentiation so that tumour hypoxia, while not totally inhibiting differentiation, might arrest it at some point short of end stage differentiation. Cell lines derived from a poorly differentiated squamous cell carcinoma, for example, can express involucrin without losing proliferative capability (Auersperg et al, 1989). This is also true of SCC9 cells where confluent cells are easily subcultured in spite of possessing substantial levels of involucrin. Clearly, the presence of involucrin need not be a sign of end stage differentiation and further work will be required to define the extent to which hypoxic cells in squamous cell carcinomas are differentiated. This could be important because it is known that differentiation increases radiosensitivity in human carcinoma cells under both hypoxic and aerobic conditions (Hallows et al, 1988; Hoffmann et al, 1999). Radiosensitisation might be due to inhibited DNA repair arising from the limited access of DNA repair machinery in differentiated cells (Wheeler and Wierowski, 1983). To the extent that the in vitro results apply clinically, hypoxic cells that are more differentiated might be less radioresistant than otherwise thought.

A recurring theme in the study of endogenous hypoxia markers - whether it be HIF- $1 \alpha$, CAIX, Glut-1 or involucrin - is heterogeneity of expression (Olive et al, 2001; Wiesener et al, 2001; Haugland et al, 2002; Janssen et al, 2002; Kaanders et al, 2002; Airley et al, 2003). The basis for heterogeneity in the case of involucrin appears to be related to cell differentiation. In the case of HIF- $1 \alpha$, functional inactivation of the von Hippel Lindau factor might be the most important factor (Wiesener et al, 2001; Haugland et al, 2002; Janssen et al, 2002; Turner et al, 2002). Endogenous ORPs appear to be useful as hypoxia markers in normal tissues (e.g. Lee et al, 2001), but without a good understanding of the factors that control ORP expression, heterogeneity of expression of proteins such as involucrin will limit their scope as markers of human tumour hypoxia.

\section{ACKNOWLEDGEMENTS}

The Financial support was supplied by Department of Health and Human Services Grants CA85361, CA68826 and RR00046 and by the State of North Carolina. We are indebted to Ms Lisa Licht, RN for the management of the clinical aspects of the study and we thank Ms Esterine Thompson for valuable administrative assistance.

\section{REFERENCES}

Airley RE, Loncaster J, Raleigh JA, Harris AL, Davidson SE, Hunter RD, West CM, Stratford IJ (2003) GLUT-1 and CAIX as intrinsic markers of hypoxia in carcinoma of the cervix: relationship to pimonidazole binding. Int J Cancer 104: 85-91

Arteel G, Thurman R, Raleigh J (1998) Reductive metabolism of the hypoxia marker pimonidazole is regulated by oxygen tension independent of the pyridine nucleotide redox state. Eur J Biochem 253: $743-750$

Arteel GE, Thurman RG, Yates JM, Raleigh JA (1995) Evidence that hypoxia markers detect oxygen gradients in liver: pimonidazole and retrograde perfusion of rat liver. Br J Cancer 72: 889-895

Auersperg N, Kruk PA, MacLaren IA, Watt FM, Mydral SE (1989) Heterogeneous expression of keratin, involucrin, and extracellular matrix among subpopulations of a poorly differentiated human cervical carcinoma: possible relationships to patterns of invasion. Cancer Res 49: $3007-3014$

Azuma Y, Chou S-C, Lininger RA, Murphy BJ, Varia MA, Raleigh JA (2003) Hypoxia and differentiation in squamous cell carcinomas of the uterine cervix: pimonidazole and involucrin. $\mathrm{Cl}$ Cancer Res 9: 4944-4952

Bandyopadhyay RS, Phelan M, Faller DV (1995) Hypoxia induces AP-1-regulated genes and AP-1 transcription factor binding in human endothelial and other cell types. Biochim Biophys Acta 1264: $72-78$

Boag J (1969) Oxygen diffusion and oxygen depletion problems in radiobiology. Curr Top Radiat Res 5: $141-195$

Chiarotto JA, Hill RP (1999) A quantitative analysis of the reduction in oxygen levels required to induce up-regulation of vascular endothelial growth factor (VEGF) mRNA in cervical cancer cell lines. Br J Cancer 80: $1518-1524$

Claffey KP, Wilkison WO, Spiegelman BM (1992) Vascular endothelial growth factor. Regulation by cell differentiation and activated second messenger pathways. J Biol Chem 267: 16317-16322
Crish JF, Bone F, Banks EB, Eckert RL (2002) The human involucrin gene contains spatially distinct regulatory elements that regulate expression during early versus late epidermal differentiation. Oncogene 21: 738-747

Denda M, Hosoi J, Asida Y (2000) Visual imaging of ion distribution in human epidermis. Biochem Biophys Res Commun 272: 134-137

Eckert RL, Welter JF (1996) Transcription factor regulation of epidermal keratinocyte gene expression. Mol Biol Rep 23: 59-70

Efimova T, LaCelle P, Welter JF, Eckert RL (1998) Regulation of human involucrin promoter activity by a protein kinase C, Ras, MEKK1, MEK3, p38/RK, AP1 signal transduction pathway. J Biol Chem 273: 24387-24395

Franko AJ, Koch CJ, Garrecht BM, Sharplin J, Hughes D (1987) Oxygen dependence of binding of misonidazole to rodent and human tumors in vitro. Cancer Res 47: $5367-5376$

Franko AJ, Parliament MB, Allalunis-Turner MJ, Wolokoff BG (1998) Variable presence of hypoxia in M006 human glioma spheroids and in spheroids and xenografts of clonally derived sublines. Br J Cancer 78: $1261-1268$

Fyles A, Milosevic M, Hedley D, Pintilie M, Levin W, Manchul L, Hill RP (2002) Tumor hypoxia has independent predictor impact only in patients with node-negative cervix cancer. J Clin Oncol 20: 680-687

Gaido KW, Maness SC (1994) Regulation of gene expression and acceleration of differentiation in human keratinocytes by $2,3,7,8$ tetrachlorodibenzo-p-dioxin. Toxicol Appl Pharmacol 127: 199-208

Gibson DF, Ratnam AV, Bikle DD (1996) Evidence for separate control mechanisms at the message, protein, and enzyme activation levels for transglutaminase during calcium-induced differentiation of normal and transformed human keratinocytes. J Invest Dermatol 106: 154-161

Gross MW, Karbach U, Groebe K, Franko AJ, Mueller-Klieser W (1995) Calibration of misonidazole labeling by simultaneous measurement of oxygen tension and labeling density in multicellular spheroids. Int J Cancer 61: 567-573 
Hallows KR, Bliven SF, Leith JT (1988) Effects of the differentiating agents sodium butyrate and $\mathrm{N}$-methylformamide on the oxygen enhancement ratio of human colon tumor cells. Radiat Res 113: 191- 198

Haugland HK, Vukovic V, Pintilie M, Fyles AW, Milosevic M, Hill RP, Hedley DW (2002) Expression of hypoxia-inducible factor-1alpha in cervical carcinomas: correlation with tumor oxygenation. Int J Radiat Oncol Biol Phys 53: 854-861

Helczynska K, Kronblad A, Jogi A, Nilsson E, Beckman S, Landberg G, Pahlman S (2003) Hypoxia promotes a dedifferentiated phenotype in ductal breast carcinoma in situ. Cancer Res 63: 1441-1444

Hockel M, Schlenger K, Aral B, Mitze M, Schaffer U, Vaupel P (1996a) Association between tumor hypoxia and malignant progression in advanced cancer of the uterine cervix. Cancer Res 56: 4509-4515

Hockel M, Schlenger K, Hockel S, Vaupel P (1999) Hypoxic cervical cancers with low apoptotic index are highly aggressive. Cancer Res 59: $4525-4528$

Hockel M, Schlenger K, Mitze M, Schaffer U, Vaupel P (1996b) Hypoxia and radiation response in human tumors. Sem Rad Oncol 6: 3-9

Hoffmann W, Blase MA, Santo-Hoeltje L, Herskind C, Bamberg M, Rodemann HP (1999) Radiation sensitivity of human squamous cell carcinoma cells in vitro is modulated by all-trans and 13-cis-retinoic acid in combination with interferon-alpha. Int J Radiat Oncol Biol Phys 45: $991-998$

Janssen HL, Haustermans KM, Sprong D, Blommestijn G, Hofland I, Hoebers FJ, Blijweert E, Raleigh JA, Semenza GL, Varia MA, Balm AJ, van Velthuysen ML, Delaere P, Sciot R, Begg AC (2002) HIF-1alpha, pimonidazole, and iododeoxyuridine to estimate hypoxia and perfusion in human head-and-neck tumors. Int J Radiat Oncol Biol Phys 54: $1537-1549$

Jiang BH, Semenza GL, Bauer C, Marti HH (1996) Hypoxia-inducible factor 1 levels vary exponentially over a physiologically relevant range of $\mathrm{O}_{2}$ tension. Am J Physiol 271: C1172-1180

Jones DP (1985) The role of oxygen concentration in oxidative stress: hypoxic and hyperoxic models. In: Oxidative Stress, Sies H (ed) pp 151 - 195. New York: Academic Press

Kaanders HAM, Wijffels KIEM, Marres HAM, Ljungkvist ASE, Pop LAM, van den Hoogen FJA, de Wilde PCM, Bussink J, Raleigh JA, van der Kogel AJ (2002) Patient selection for hypoxia-modifying treatments based on pimonidazole binding and tumor vascularity. Cancer Res 62: $7066-7074$

Kaluz S, Kaluzova M, Chrastina A, Olive PL, Pastorekova S, Pastorek J, Lerman MI, Stanbridge EJ (2002) Lowered oxygen tension induces expression of the hypoxia marker MN/carbonic anhydrase IX in the absence of hypoxia-inducible factor lalpha stabilization: a role for phosphatidylinositol 3'-kinase. Cancer Res 62: 4469-4477

Kennedy AS, Raleigh JA, Perez GM, Calkins DP, Thrall DE, Novotny DB, Varia MA (1997) Proliferation and hypoxia in human squamous cell carcinoma of the cervix: first report of combined immunohistochemical assays. Int J Radiat Oncol Biol Phys 37: 897-905

Koch CJ, Evans SM, Lord EM (1995) Oxygen dependence of cellular uptake of EF5 [2-(2-nitro-1H-imidazol-1- yl)-N-(2,2,3,3,3-pentafluoropropyl)a cet amide]: analysis of drug adducts by fluorescent antibodies $v s$ bound radioactivity. $\mathrm{Br} J$ Cancer 72: 869-874

Laderoute KR, Calaoagan JM, Gustafson-Brown C, Knapp AM, Li GC, Mendonca HL, Ryan HE, Wang Z, Johnson RS (2002) The response of c-jun/AP-1 to chronic hypoxia is hypoxia-inducible factor 1 alpha dependent. Mol Cell Biol 22: 2515-2523

Lee YM, Jeong CH, Koo SY, Son MJ, Song HS, Bae SK, Raleigh JA, Chung HY, Yoo MA, Kim KW (2001) Determination of hypoxic region by hypoxia marker in developing mouse embryos in vivo: a possible signal for vessel development. Dev Dyn 220: 175-186

Leith JT, Michelson S (1995) Secretion rates and levels of vascular endothelial growth factor in clone A or HCT-8 human colon tumour cells as a function of oxygen concentration. Cell Prolif 28: 415-430

Levy FH, Kelly DP (1997) Regulation of ATP synthase subunit e gene expression by hypoxia: cell differentiation stage-specific control. Am J Physiol 272: C457-C465

Murphy BJ, Andrews GK, Bittel D, Discher DJ, McCue J, Green CJ, Yanovsky M, Giaccia A, Sutherland RM, Laderoute KR, Webster KA (1999) Activation of metallothionein gene expression by hypoxia involves metal response elements and metal transcription factor-1. Cancer Res 59: 1315-1322

Nordsmark M, Overgaard M, Overgaard J (1996) Pretreatment oxygenation predicts radiation response in advanced squamous cell carcinoma of the head and neck. Radiother Oncol 41: 31-39
Olive PL, Aquino-Parsons C, MacPhail SH, Liao SY, Raleigh JA, Lerman MI, Stanbridge EJ (2001) Carbonic anhydrase 9 as an endogenous marker for hypoxic cells in cervical cancer. Cancer Res 61: 8924-8929

Parliament MB, Franko AJ, Allalunis-Turner MJ, Mielke BW, Santos CL, Wolokoff BG, Mercer JR (1997) Anomalous patterns of nitroimidazole binding adjacent to necrosis in human glioma xenografts: possible role of decreased oxygen consumption. Br J Cancer 75: 311-318

Pigott KH, Hill SA, Chaplin DJ, Saunders MI (1996) Microregional fluctuations in perfusion within human tumours detected using laser Doppler flowmetry. Radiother Oncol 40: 45-50

Quaife CJ, Findley SD, Erickson JC, Froelick GJ, Kelly EJ, Zambrowicz BP, Palmiter RD (1994) Induction of a new metallothionein (MT-IV) during differentiation of stratified squamous epithelia. Biochemistry 33: $7250-7259$

Raleigh J, Chou S-C, Calkins-Adams D, Ballenger C, Novotny D, Varia M (2000) A clinical study of hypoxia and metallothionein protein expression in squamous cell carcinomas. Clin Cancer Res 6: $855-862$

Raleigh JA, Calkins-Adams DP, Rinker LH, Ballenger CA, Weissler MC, Fowler WC, Novotny DB, Varia MA (1998a) Hypoxia and vascular endothelial growth factor expression in human squamous cell carcinomas using pimonidazole as a hypoxia marker. Cancer Res 58: 3765-3768

Raleigh JA, Chou S-C, Arteel GE, Horsman MR (1999) Comparisons among pimonidazole binding, oxygen electrode measurements and radiation response in C3H mouse tumors. Radiat Res 151: 580-589

Raleigh JA, Chou S-C, Tables LL, Suchindran S, Varia MA, Horsman MR (1998b) Relationship of hypoxia to metallothionein expression in murine tumors. Int J Radiat Oncol Biol Phys 42: 727-730

Raleigh JA, La Dine JK, Cline JM, Thrall DE (1994) An enzyme-linked immunosorbent assay for hypoxia marker binding in tumours. Br J Cancer 69: 66-71

Rheinwald JG, Beckett MA (1980) Defective terminal differentiation in culture as a consistent and selectable character of malignant human keratinocytes. Cell 22: 629-632

Rheinwald JG, Beckett MA (1981) Tumorigenic keratinocyte lines requiring anchorage and fibroblast support cultures from human squamous cell carcinomas. Cancer Res 41: 1657-1663

Rice RH, Rong XH, Chakravarty R (1988) Suppression of keratinocyte differentiation in SSC-9 human squamous carcinoma cells by benzo[a]pyrene, 12-O-tetradecanoylphorbol-13-acetate and hydroxyurea. Carcinogenesis 9: $1885-1890$

Roland NJ, Rowley H, Scraggs M, Johnson P, Jones AS (1996) MIB-1 and involucrin expression in laryngeal squamous carcinoma: the relationship to host and tumour factors and survival. Clin Otolaryngol 21: 429-438

Sahai A, Mei C, Zavosh A, Tannen RL (1997) Chronic hypoxia induces LLCPK1 cell proliferation and dedifferentiation by the activation of protein kinase C. Am J Physiol 272: F809-F815

Salnikow K, Kluz T, Costa M, Piquemal D, Demidenko ZN, Xie K, Blagosklonny MV (2002) The regulation of hypoxic genes by calcium involves c-Jun/AP-1, which cooperates with hypoxia-inducible factor 1 in response to hypoxia. Mol Cell Biol 22: 1734-1741

Shweiki D, Itin A, Soffer D, Keshet E (1992) Vascular endothelial growth factor induced by hypoxia may mediate hypoxia-initiated angiogenesis. Nature 359: 843-845

Sundelin K, Jadner M, Norberg-Spaak L, Davidsson A, Hellquist HB (1997) Metallothionein and Fas (CD95) are expressed in squamous cell carcinoma of the tongue. Eur J Cancer 33: 1860-1864

Takahashi H, Iizuka H (1993) Analysis of the 5'-upstream promoter region of human involucrin gene: activation by 12-O-tetradecanoylphorbol-13acetate. J Invest Dermatol 100: $10-15$

Thrall DE, McEntee MC, Cline JM, Raleigh JA (1994) ELISA quantification of CCI-103F binding in canine tumors prior to and during irradiation. Int J Radiat Oncol Biol Phys 28: 649-659

Turcotte ML, Parliament M, Franko A, Allalunis-Turner J (2002) Variation in mitochondrial function in hypoxia-sensitive and hypoxia-tolerant human glioma cells. Br J Cancer 86: 619-624

Turner KJ, Moore JW, Jones A, Taylor CF, Cuthbert-Heavens D, Han C, Leek RD, Gatter KC, Maxwell PH, Ratcliffe PJ, Cranston D, Harris AL (2002) Expression of hypoxia-inducible factors in human renal cancer: relationship to angiogenesis and to the von Hippel-Lindau gene mutation. Cancer Res 62: 2957-2961

Varia MA, Calkins-Adams DP, Rinker LH, Kennedy AS, Novotny DB, Fowler WC, Raleigh JA (1998) Pimonidazole: a novel hypoxia marker for complementary study of tumor hypoxia and cell proliferation in cervical carcinoma. Gynecol Oncol 71: 270-277 
Viac J, Palacio S, Schmitt D, Claudy A (1997) Expression of vascular endothelial growth factor in normal epidermis, epithelial tumors and cultured keratinocytes. Arch Dermatol Res 289: 158 - 163

Watt FM (1983) Involucrin and other markers of keratinocyte terminal differentiation. J Invest Dermatol 81: 100s-103s

Webster KA, Gunning P, Hardeman E, Wallace DC, Kedes L (1990) Coordinate reciprocal trends in glycolytic and mitochondrial transcript accumulations during the in vitro differentiation of human myoblasts. J Cell Physiol 142: 566-573

Wheeler KT, Wierowski JV (1983) DNA accessibility: a determinant of mammalian cell differentiation? Radiat Res 93: 312-318

Whillans DW, Rauth AM (1980) An analysis of changes in oxygen tension in stirred cellular suspensions under conditions of radiolytic and cellular consumption. Cancer Clin Trials 3: 63-67
Wiesener MS, Munchenhagen PM, Berger I, Morgan NV, Roigas J, Schwiertz A, Jurgensen JS, Gruber G, Maxwell PH, Loning SA, Frei U, Maher ER, Grone HJ, Eckardt KU (2001) Constitutive activation of hypoxia-inducible genes related to overexpression of hypoxiainducible factor-1alpha in clear cell renal carcinomas. Cancer Res 61: $5215-5222$

Wykoff CC, Beasley NJ, Watson PH, Turner KJ, Pastorek J, Sibtain A, Wilson GD, Turley H, Talks KL, Maxwell PH, Pugh CW, Ratcliffe PJ, Harris AL (2000) Hypoxia-inducible expression of tumor-associated carbonic anhydrases. Cancer Res 60: 7075-7083

Zhong Z, Arteel GE, Connor HD, Yin M, vonFrankenberg M, Stachlewitz RF, Raleigh JA, Mason RP, Thurman RG (1998) Cyclosporin A increases hypoxia and free radical production in rat kidneys: prevention by dietary glycine. Am J Physiol 275 (Renal Physiol): F595 - F604 